CSID Working Paper Series

\#CSID-2013-002

\title{
Robustness of Social-Ecological Systems: Implications for Public Policy
}

\author{
John M. Anderies \\ Arizona State University, USA \\ Marco A. Janssen \\ Arizona State University, USA
}

January 7, 2013

The Center for the Study of Institutional Diversity resides in the School of Human Evolution and Social Change at Arizona State University. CSID can be found on the internet at: http://csid.asu.edu. CSID can be reached via email at csid@asu.edu. 


\section{Robustness of Social-Ecological Systems: Implications for Public Policy}

John M. Anderies ${ }^{a}$, Marco A. Janssen ${ }^{b}$,

${ }^{a}$ Center for the Study of Institutional Diversity, Arizona State University, Tempe, AZ 85287-2402, USA;

${ }^{b}$ Center for the Study of Institutional Diversity, Arizona State University, Tempe, AZ 85287-2402, USA;

Corresponding author:

John M. Anderies

School of Human Evolution and Social Change

School of Sustainability

Arizona State University

PO Box 87402

Tempe, AZ 85287-2402, USA

m.anderies@asu.edu

\section{Keywords:}

Robustness, SES, Public Policy, Policy Processes. 


\title{
Robustness of Social-Ecological Systems: Implications for Public Policy
}

\author{
John M. Anderies* $\quad$ Marco A. Janssen ${ }^{\dagger}$
}

January 7, 2013

\section{Introduction}

Public policy processes are complex, dynamic phenomena. Understanding such dynamic phenomenon requires some sort of strategy for simplification - some way to isolate key system components and relationships among them that can be generalized to understand how the system structure defined by these components and relationships relates to policy outcomes across various contexts. There has been steady development of improved policy theory (Sabatier et al., 1999, 2007) focusing on better understanding how actors, problems, solutions, and decision opportunities interact to generate policy change. Such theories often focus on explaining policy change within a given organizational context that defines decision venues, restricts how agents interact, determines costs and benefits of interactions and particular outcomes. Given the notion of a policy cycle, or some period for a policy change of interest to play out, it is often reasonable to assume that key elements of the policy context remain stable. The Advocacy Coalition Framework (Sabatier, 1988) makes this explicit by defining "relatively stable parameters" that frame the policy process: (1) basic attributes of the problem area, (2) basic distribution of natural resources, (3) fundamental socio-cultural values and social structure, and (4) basic constitutional structure (Sabatier and Jenkins-Smith, 1993) that are assumed to remain stable for approximately 100 years or more. It is on these relatively stable parameters that we focus our attention here.

Specifically, we present a framework that seeks to link the notion of the policy process to the policy context and provide a systematic approach to understand the dynamic interaction between the two. The main intent of the framework is to embed the policy process in a dynamically evolving policy context, driven by the feedbacks between biophysical processes and policy processes. Viewed in this way, the policy process can be understood as an emergent property of a dynamic, underlying social-ecological system. The framework is based on ideas from institutional rational choice and an extension of the Institutional Analysis and Development (IAD) framework, familiar to many policy scholars. The main contribution of this article and the framework it presents is to provide ideas, language, and tools to move, when appropriate, from the conception of the policy process shown in Figure 1 (A) in which a fixed policy context generates streams of challenges which are processed by policy subsystems in which human actors and human-made infrastructure interact to the conception pictured in Figure 1 (B) in which policies drive the dynamics of the biophysical system (natural infrastructure) in which they are embedded, generating new information that feeds back into the policy process.

\footnotetext{
${ }^{*}$ School of Human Evolution, Social Change and School of Sustainability and Center for the Study of Institutional Diversity, Arizona State University

${ }^{\dagger}$ School of Human Evolution and Social Change and Center for the Study of Institutional Diversity, Arizona State University
} 


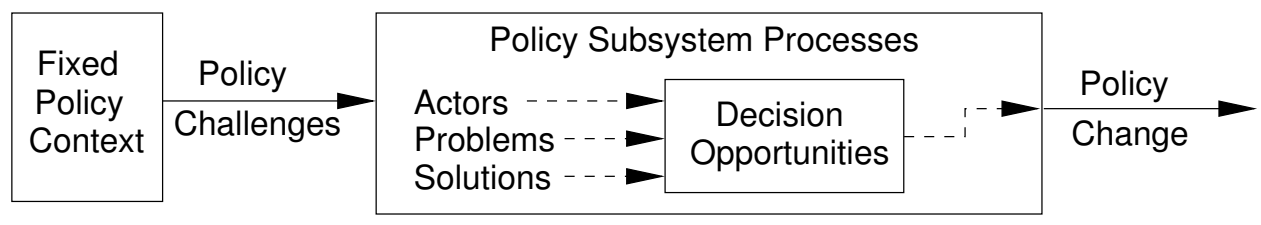

(A)

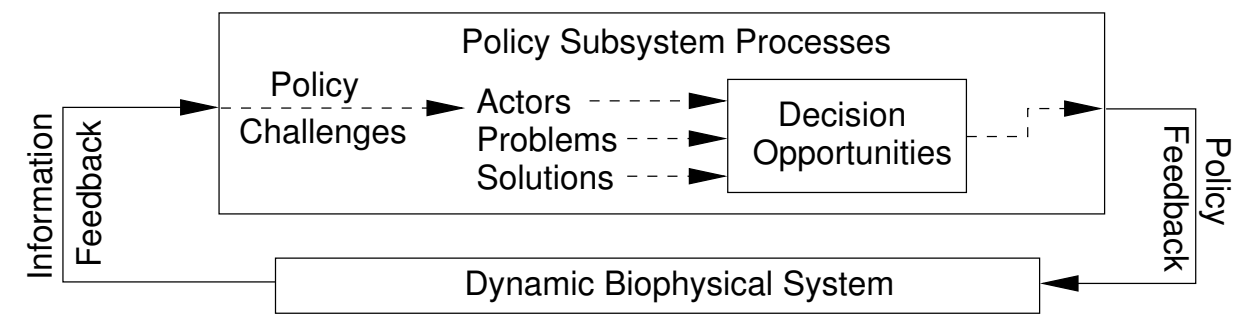

(B)

Figure 1: (A): The policy process as a flow-through system in which policy challenges generated in a fixed policy context are processed and produce policy change. (B): The policy process as part of a dynamic, self-organizing feedback system.

\section{Changing scales and new public policy theory}

Both conceptions of the policy process shown in Figure 1 are perfectly reasonable. Which one to choose is a matter of the relative social, biophysical, and temporal scales relevant to the problem of interest. These relative scales determine the degree of connectedness between different components of policy subsystems and the policy context. Note, in the ACF, the policy context is assumed to be constant over periods on the order of a century (Weible and Sabatier, 2007). Often, this is a reasonable assumption, and Figure 1 (A) is the appropriate view. It may be necessary to shift to the representation in Figure 1 (B) when the amplitude or frequency of variation in the policy context becomes to high, and the feedbacks become too fast.

For example, consider some very old public policy developed when the overall scale of human activity was small. The Code of Hammurabi deals with very specific types of risk: if a landlord lets his land for fixed rental fee, if bad weather destroys the harvest, the code specifies that the injury falls upon the tenant. In rental contracts based on harvest shares, on the other hand, the landlord and tenant share the risk of crop loss (and the potential benefit of a bumper crop). The numerous references in Hammurabi's code to risk and environmental variability is a testamant to how long public policy has had to address environmental variability. Further, the focus on assignment of risk and emphasis on clear delineation of social roles (positon rules sensu Ostrom, 1990, 2005) suggests that the main challenge for public policy in early societies was the smooth functioning of society in general, and in the face of ever present environmental variation, in particular. More specifically, because the scale of human society was small,1) public policy focused on the tight connection between the individual and local biophysical context and 2) the links between public policy and the larger regional- or continental-scale biophysical context (e.g. that affect the distribution of weather events) were weak, and feedbacks were very slow. In this case, Figure 1 (A) is a good representation of the system: the policy context is fixed, delivering a reasonably stable distribution of exogenously driven weather events (shocks). These shocks impacted individuals who likely had reasonable information about expected payoffs and could choose contracts. Here, public policy, or the code, is a constraint regarding what types of contracts are allowed for spreading risk and reducing conflict.

The types of environmental challenges we face today cannot be treated as exogenous shocks affecting individuals who can attempt to insure against them. The scale of the human enterprise has reached a point where human actions are becoming more tightly coupled to larger-scale environmental processes. We now, 
for example, measurably impact global biogeochemical cycles (Vitousek et al., 1997). In such circumstances, individual human actions add up to generate impacts that fundamentally change the nature of the policy context. There are two key questions that arise in this regard: 1) can the policy process, which often plays out on the order of decades, possibly function when the policy context changes rapidly?, and 2) when the policy process and policy context involving a dynamic biophysical system co-evolve as the a coupled feedback system depicted in Figure 1 (B), does infrastructure (socio-technical structures) emerge that makes the system rigid and vulnerable to novel change? These questions are critical for public policy in the modern context in which globalization and global environmental change are generating a highly connected globalscale system in which decisions at small scales are influenced by and will influence processes at the global scale in unpredictable and novel ways (Adger et al., 2009). Will public policy (and societies themselves) be able to respond to the shear pace at which social and natural systems are currently changing? If faced with one of either natural or social change, perhaps the answer is yes. However, in the face of simultaneous impacts of global environmental change and globalization (O'Brien and Leichenko, 2000), they may not be able to cope.

How do we conduct the public policy process in coupled social-ecological systems (SESs) when the temporal and spatial scales of both human activity and our impacts on biophysical dynamics has fundamentally changed, and when traditional approach of providing the best option to a concrete problem is insufficient? Here we describe a set of ideas and tools designed to analyze dynamic feedback systems of which the class of SESs depicted in Figure 1 (B) are examples. To do so, we will briefly define social-ecological systems and present the robustness and SES frameworks to analyze how systems deal with disturbances and stress. We will illustrate the use of the framework to examine the fit between institutional arrangements and ecological dynamics (i.e. how well does public policy perform). The idea of "fit" is realized by characterizing trade-offs in the capacity of the SES to cope with different types of shocks. These trade-offs arise as a result of a fundamental property of feedback systems - conservation of fragility (or vulnerability). Put simply, this implies that it is not possible to design public policy for a given ecological (environmental) context - i.e. achieve a "fit" so that the SES is robust to all possible shocks. Thus, one aspect of the public policy process is effectively navigating trade-offs between performance and robustness and choices between different vulnerabilities. We will discuss possible approaches to this policy challenge with reference to ideas from robust control that emphasizes system properties such as modularity, diversity and redundancy; and through reflections on the polycentric approach of Ostrom.

\section{The SES Framework and Public Policy}

The idea of a "coupled social ecological system" emerged in response to what was seen as failed resource management policy from the 1970's to the early 1990's. Several scholars recognized that in most cases, management policy resulted in unintended consequences because they neglected the coupling between social and ecological systems. Early collaborations between mathematical biologists and theoretical ecologists extending ideas from systems theory (feedback systems like that in Figure 1 (B)) focused on how "fast" and "slow" processes interact to generate cycles of change ecological systems. The big message was that ecological systems do NOT tend toward a stable "climax" state (Clements, 1916) characterized by stable distributions of species such as an old growth forest that management policy should seek to maintain. Rather, management policy, and by extension, public policy must be designed to manage complex cyclical dynamics and acknowledge the potential for abrupt regime shifts(Gunderson et al., 2008; Holling and Gunderson, 2002; Ludwig et al., 1997; Holling, 1979; Ludwig et al., 1978; Holling, 1978, 1973). A regime shift occurs when the key drivers in a system fundamentally change. A well-known example is when key drivers that affect the dynamics of phosphorous concentration in the water column change and the water shifts from clear blue (oligotrophic) to green and turbid (eutrophic). Examples of regime shifts in the social domain are 


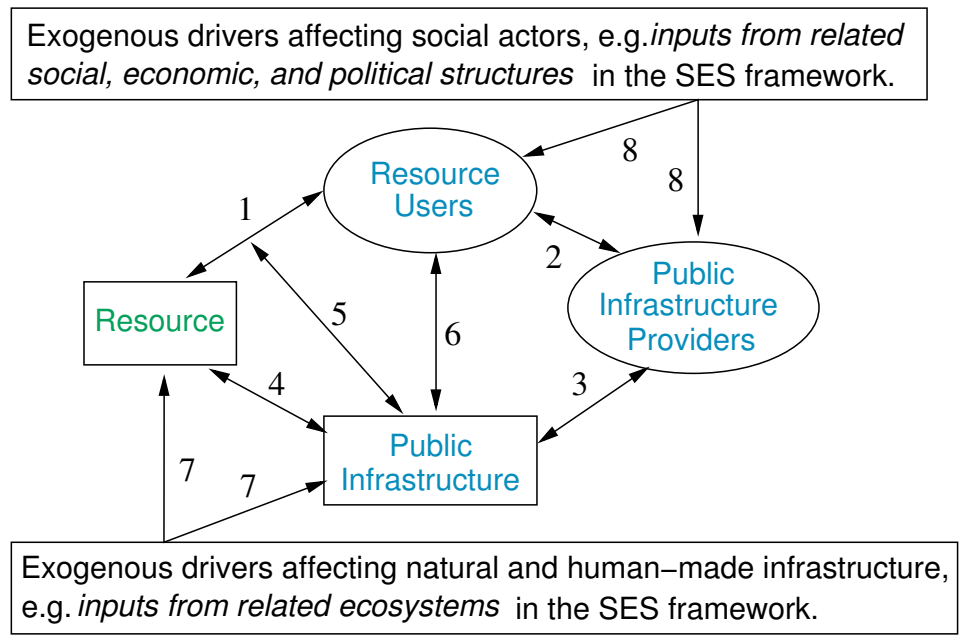

Figure 2: The robustness framework (adapted from Anderies et al., 2004). Details of the external drivers and embedding were not specified in the original framework but are added here to illustrate the correspondence between the robustness framework and the SES framework (Figure 3). The color coding illustrates the rough correspondence between entities in the frameworks.

easy to imagine.

Much of this work was centered around theoretical ecology and resource economics, driven by Buzz Holling and his collaborators. Holling's observations of repeated resource management failures led him to define what he called the "command and control pathology of natural resource management" (Holling and Meffe, 1996). At the same time in a completely different field, political science, Ellinor Ostrom was also questioning the rationality of top down, command and control governance structures (Ostrom, 1990). Ostroms argument was very powerful: small groups of people can effectively manage complex resource systems without top down governance structures. Fortunately these research trajectories converged at the policy/governance ecological dynamics interface (Berkes et al., 2003) and the concept of social-ecological systems (SES) was formalized. Through her collaborations with ecologists, economists, and dynamical systems theorists in the resilience community, she worked for over a decade to connect her groundbreaking work on the IAD framework for institutional and public policy analysis to features of the biophysical context in which they operate. The result was the SES framework.

The development of the SES framework was motivated, in part, by the perceived need to understand governance under uncertainty of the kind emphasized by resilience theorists - the potential for dramatic regime shifts - i.e. lakes that flip from oligotrophic and eutrophic conditions (Carpenter et al., 1999) and policy choice in the face of potential catastrophic regime shifts (Brock et al., 2005). Because institutions are often explicitly designed to cope with particular types of uncertainty, the concepts of robustness and robust controls were a natural place to begin. This led to the framework to study robustness SESs from an institutional perspective shown in Figure 2.

This framework, developed by Anderies et al. (2004), emphasized the distinction between actors (shown in ovals) and infrastructure (shown as rectangles) and the relationship between those who use the resource, and those who may control it (public infrastructure providers), i.e. link 2 in Figure 2. Public policy enters the framework with public infrastructure. Public policy-the output of the public policy process- is a type of public infrastructure (e.g. legal systems) that in the case of resource management affects the relationship between resource users and the resource itself (link 1) through link 5. A simple example is a regulation such as an effort quota: resource users can only harvest from the resource so many days per year - a common public policy measure in fisheries in the recent past. Also included with public infrastructure is hard infrastructure 


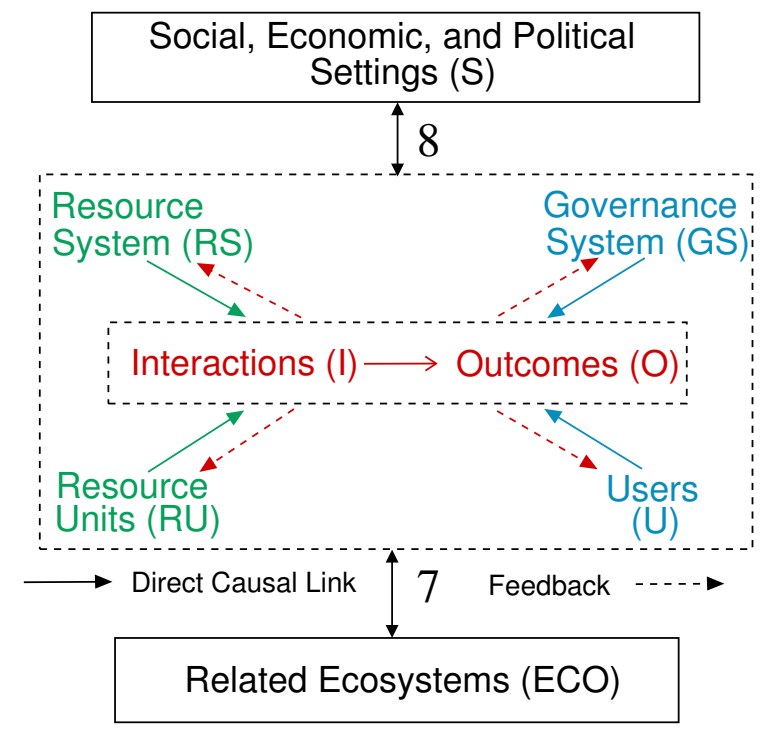

Figure 3: First generation SES framework (adapted from Ostrom, 2007). The original framework did not include the numbers 7 or 8 on the links between exogenous drivers and the system in question. These have been added to show the correspondence between the SES framework and the robustness framework in Figure 2. The color coding illustrates the rough correspondence between entities in the frameworks.

- bridges, roads, irrigation canals - also the subject of public investment, and thus of public policy. Link 6 highlights the importance of coproduction, the direct involvement of resource users that is often essential in the provision of public infrastructure (Ostrom, 1996; Parks et al., 1981).

As discussed earlier, the emphasis of this framework was not on the performance of particular policies, per se. Rather, the focus was on the basic structure of relationships 1-6 and how they might cope with environmental shocks (arrows 7) such as floods (impact on public infrastructure) or drought (impact on resource) and social, political, economic shocks (arrows 8). The first generation SES framework in Figure 3 is similar to the robustness framework conceptually, but returned its focus to understanding targeted public policy questions in the context of natural resource management. The methodological basis for the framework, which Ostrom referred to as "a multitier framework for analyzing an SES" was based on a diagnostic approach, motivated by the analogue of diagnosis in the medical field. The systems that medical professionals work with are extraordinarily complex, and medical professionals have steadily moved away from simple panaceas - the simple remedies of the past. Ostrom argues that some policy practitioners have not come as far and still rely too much on panaceas (privatization, cap and trade). Each particular resource system has special characteristics that require careful policy design. Resource systems (or any system composed of human-made natural infrastructure) requires a tailored policy cure, analogous to personalized medicine. Ostrom's initial multitier framework provided a tool to diagnose the problem and find a cure.

It is clear by comparing Figures 2 and 3, that the multitier framework is a special case of the robustness framework. The exogenous drivers of resource dynamics (arrow 7) were assumed to be quite general in the robustness framework. In the SES framework, these were replaced by related ecosystems. Likewise, the exogenous drivers of the Resource Users (RU), Public Infrastructure Providers (PIP) (arrows 8), and the Public Infrastructure (PI) itself (arrow 7) have been instantiated as Social, Economic, and Political Settings in the SES framework. In the Robustness Framework, the "Governance System" was conceptualized as the dynamic interaction between RUs, PIPs, PI via links 2, 3, and 6. In this view, PI includes both "soft" and "hard" infrastructure necessary to govern a system. In the multitier framework in Figure 3, PI and PIP's are 


\begin{tabular}{|c|c|}
\hline \multicolumn{2}{|c|}{$\begin{array}{c}\text { Social, economic, and political settings (S) } \\
\text { S1 Economic development. S2 Demographic trends. S3 Political stability } \\
\text { S4 Government resource policies. S5 Market incentives. S6 Media organization. } \\
\text { (Note: In the Robustness Framework of Anderies et al. (2004), these are examples of exogenous drivers 8) }\end{array}$} \\
\hline Resource systems (RS) & Governance systems (GS) \\
\hline $\begin{array}{l}\text { RS1 Sector (e.g., water, forests, pasture, fish) }(\mathbf{R + 1 + 6}) \\
\text { RS2 Clarity of system boundaries }(\mathbf{R + P I + 1 + 5 )} \\
\text { RS3 Size of resource system* }(\mathbf{R}) \\
\text { RS4 Human-constructed facilities (PI) } \\
\text { RS5 Productivity of system }(\mathbf{R + 7}) \\
\text { RS6 Equilibrium properties }(\mathbf{R}) \\
\text { RS7 Predictability of system dynamics* }(\mathbf{R + P I + 4 + 7 )} \\
\text { RS8 Storage characteristics }(\mathbf{R + P I + 4 )} \\
\text { RS9 Location (R) }\end{array}$ & $\begin{array}{l}\text { GS1 Government organizations (PI+PIP) } \\
\text { GS2 Nongovernment organizations (PI+PIP) } \\
\text { GS3 Network structure (RU+PIP+2) } \\
\text { GS4 Property-rights systems (PI) } \\
\text { GS5 Operational rules (PI) } \\
\text { GS6 Collective-choice rules* }(\mathbf{P I}) \\
\text { GS7 Constitutional rules }(\mathbf{P I}) \\
\text { GS8 Monitoring and sanctioning processes (PIP+3) }\end{array}$ \\
\hline Resource units (RU) & Users (U) \\
\hline $\begin{array}{l}\text { RU1 Resource unit mobility }{ }^{*}(\mathbf{R}) \\
\text { RU2 Growth or replacement rate (R) } \\
\text { RU3 Interaction among resource units (R+7+PI) } \\
\text { RU4 Economic value (R+7) } \\
\text { RU5 Number of units }(\mathbf{R}) \\
\text { RU6 Distinctive markings (R) } \\
\text { RU7 Spatial and temporal distribution (R) }\end{array}$ & $\begin{array}{l}\text { U1 Number of users* }(\mathbf{R U}+\mathbf{1}) \\
\text { U2 Socioeconomic attributes of users (RU) } \\
\text { U3 History of use }(\mathbf{R U + 1 )} \\
\text { U4 Location }(\mathbf{R U}) \\
\text { U5 Leadership/entrepreneurship* }(\mathbf{R U + 1 + 2 + 6 )} \\
\text { U6 Norms/social capital* }(\mathbf{R U + 6 )} \\
\text { U7 Knowledge of SES/mental models* }(\mathbf{R U}) \\
\text { U8 Importance of resource* }(\mathbf{R U + 1 )} \\
\text { U9 Technology used }\end{array}$ \\
\hline \multicolumn{2}{|c|}{ Interactions $(I) \longrightarrow$ Outcomes $(O)$} \\
\hline $\begin{array}{l}\text { I1 Harvesting levels of diverse users (RU) } \\
\text { I2 Information sharing among users (PI+6) } \\
\text { I3 Deliberation processes (PI+PIP+RU+2+3) } \\
\text { I4 Conflicts among users (RU) } \\
\text { I5 Investment activities (PI+PIP+RU+3+6) } \\
\text { I6 Lobbying activities (PI+PIP+3+8) } \\
\text { 17 Self-organizing activities (PI+RU+6) } \\
\text { I8 Networking activities }(6+2)\end{array}$ & $\begin{array}{l}\text { O1 Social performance measures (PI+PIP+RU+2+6) } \\
\text { (e.g., efficiency, equity, accountability, sustainability) } \\
\text { O2 Ecological performance measures (PI+PIP+RU+2+6) } \\
\text { (e.g., overharvested, resilience, biodiversity, sustainability) } \\
\text { O3 Externalities to other SESs (7) }\end{array}$ \\
\hline \multicolumn{2}{|c|}{ Related ecosystems (ECO) } \\
\hline \multicolumn{2}{|c|}{$\begin{array}{l}\text { ECO1 Climate patterns. ECO2 Pollution patterns. ECO3 Flows into and out of focal SES. } \\
\text { (Note: In the Robustness Framework of Anderies et al. (2004), these are examples of exogenous drivers 7) }\end{array}$} \\
\hline
\end{tabular}

Table 1: Examples of second-level variables under first-level core subsystems (S, RS, GS, RU, U, I, O and ECO) in Ostrom's framework for analyzing social-ecological systems presented in Ostrom (2009). In bold are cross references to elements and linkages to the robustness framework developed by Anderies et al. (2004) shown in Figure 2 (A). Note, this table is adapted from the version from Ostrom (2009) which was an extension of the initial version presented in Ostrom (2007). The asterisks refer to subset of variables found to be associated with self-organization.

replaced with "Governance System", (GS). Finally, the Resource System (RS) in Figure 3 was conceptualized as one aspect of exogenous drivers (arrow 7) or impact of infrastructure (arrow 4) on Resources in Figure 2. The resources in Figure 2 are the equivalent of Resource Units (RU) in Figure 3.

The policy process as conceptualized by policy studies scholars is captured explicitly in the robustness framework by link 3. This link referes to the dynamic interaction between PIPs - policy actors, and public infrastructure - the organizations and rules governing collective action in which the policy process plays out. Obviously, Resource Users who are affected by policy change through links 5 and 6 will enter into the policy process in a number of ways, e.g. as advocacy coalitions attempting to influence decisions of PIPs, if they 
are allowed to do so either through link 2 or 6 . The robustness framework does not specify the dynamics of the policy process. More precisely, further delineation of the nature of links 2, 3, and 6 can generate a garbage can model (Cohen et al., 1972), its more refined cousin-the multiple streams framework of Kingdon (1984, 2002), or the ACF framework (Sabatier and Jenkins-Smith, 1993).

What distinguishes the multitier framework from the robustness framework is a more systematic articulation of framework elements the relationships 1-8. Specifically, Ostrom identified second-tier variables associated with the top-tier variables depicted in Figure 3. Table 1 provides some examples of such variables. The text in bold indicates to what elements and relations in the robustness framework. Analogous to linkages in the robustness framework, the second-tier variables are an entry point for a more specific articulation for how the policy process plays out. In fact, we are now at a point to begin to understand how policy studies intersect with the robustness or SES frameworks. Specifically, we can explore how particular models of the policy process perform when coupled with particular classes of biophysical dynamics and uncertainties and in 1 (B). Here, the aim is not to explain the policy process but, rather, to explore how different possible policy processes might function in a dynamic policy context. For instance, a garbage can policy process may be well suited explore complex environments but may be very slow in developing appropriate policy for pressing problems, thus trading off short-term adaptive capacity for long-term learning. Likewise, an ACF policy process may perform well in quickly identifying alternative approaches to problems, but may crowd out exploration as actors join coalitions and build cases for particular points of view - a rather narrow type of learning. In the remainder of the paper we will attempt to illustrate how both the Robustness and SES frameworks can contribute to a collection of essential tools for public policy and governane for complexity (SES) and change (Robustness).

\section{Governance for Complexity and Change}

Using the basic elements presented in Figures 2 and/or 3 along with Table 1, it seems reasonable to assume that policy designers have enough machinery at hand to generate reasonably good policies for reasonably well-bounded policy problems. Once reasonable policy options have been identified, our understanding of how policy processes unfold, would then enable the implementation of those policies. However, what if the policy problem space is not reasonably well bounded? What if there is massive uncertainty about the links between actions and outcomes? What if the problem space encompasses a very large number of interacting elements? Such are the problem spaces we face in the environmental policy domain: biodiversity and resource management, climate change, and a globally interlinked economic system of spiraling complexity.

Here we reflect on key challenges and opportunities for governing such systems. We note that Ostrom began applying concepts from work on institutions to this problem almost 20 years ago with her work on "designing complexity to govern complexity" (Ostrom, 1995, 1998). This work stressed the importance of "complex, nested systems of governance" (Ostrom, 1995, p. 34), comprised of "quasi-autonomous units operating at quite small up to extremely large scales"(Ostrom, 1998, p.149). Ostrom suggests that the institutional design principles, derived from her work on self-governing SESs provides some guidance as to how this might be achieved. The design principles, however, were derived from a research program whose emphasis was not on dynamics and change. Thus, the design principles only address part of the picture. The need for additional tools inspired Ostrom to develop the frameworks presented here. In Section 4.1, we discuss key challenges associated with governing changing, massively uncertain systems: 1) the notion of "fit" and 2) fundamental properties of systems that must cope with change and uncertainty. In Section 4.2 we reflect on the associated set of design principles for such systems. 


\subsection{Key Challenges}

\subsubsection{The fit between institutional arrangements and ecological dynamics}

The development of frameworks to study the interactions between social and ecological systems aims to provide a systematic way to analyze diverse and complex case studies. Although we know resource users are able to overcome collective action problems to share common-pool resources and provide public goods, there is increasing interest in addressing the "problem of fit,": the interplay between institutional arrangements and ecological dynamics (Folke et al., 2007; Young, 2002). Studies of long-lasting social-ecological systems, such as fisheries, pastoralist and transhumance systems, irrigation systems, and forests show that institutions developed by those long-lasting systems are mainly based on where, when, and how to harvest, not how much to harvest (Schlager, 1994; Wilson et al., 1994; Ostrom, 2005). This suggests that an understanding of the fit between institutions and ecology needs to incorporate how human activities can match the temporal and spatial dynamics of the specific resource. In the end, this match may have the effect of regulating the amount of resources withdrawn, but the "fit", i.e. the linkages between the governance system and the resource being governed, will not be predicated on measuring harvest amounts.

Ostrom (2005) has shown in the importance of monitoring and enforcement in the effectiveness of institutional arrangements. Local resource users can be very effective in monitoring the use of the commonpool resource, especially due to their local knowledge and stake in the sustainability of the ecosystem. Paid guards from outside the local community can be effective as they may have access to better technology, especially if they are paid well. However, they may not have a stake in the SES, and thus may be prone to rent seeking behavior and may see bribes as a source of income. The spatial and temporal dynamics of ecological systems affect the ability of monitors to observe resource use. When fishers harvest fish from a large territory, farmers withdraw water from a long irrigation canal, or villagers harvest from a large forest, it is almost impossible for them to see what everyone else is currently doing. Rules on who, where, when and how to harvest are easier to monitor and enforce than a quota, and if there is more confidence that people are following the rules, others will follow them too. Could such a general principle to frame policy in terms of who, what, and when questions rather than how much questions improve public policy process outcomes? For example, policy based on science and its associated measurement protocols may make policy change impossible as attention is focused on debatable human constructs (protocols) rather than on more practical principles where measurement equates to common sense.

Many farmer-managed irrigation systems allocate a particular time to a specific farmer depending on location along the canal and size of farm (and resulting contributions to maintenance of the system) (Burns, 1993; Maass et al., 1978; Shivakoti et al., 2002). The frequent routine is to allocate a certain time block to a farmer in a specific order either from the head-end to the tail or from the tail-end to the head of the system (Meinzen-Dick, 2007; Tang, 1992). In either case, that means that when the water transfers from Farmer A to Farmer B both will be at their distribution point so that Farmer A gets as much water as possible but Farmer B is able to start watering crops on time. This system illustrates important linkages between public infrastructure, public infrastructure providers, and resource users (links 2 and 3 in Figure 2). Specifically, the nature of public infrastructure, both physical (an irrigation system) and institutional (appropriation rules based on the Spanish tanda system - i.e. timed withdrawals) coupled with the fact that the resource users in fact are the public infrastructure providers for monitoring and enforcement of rules generates an endogenous feedback system. Specifically, this arrangement brings the two most important actors for ensuring that the rule is enforced to the correct monitoring point on the canal at the correct (same) time. This is an effective way to enable two key participants to monitor what is happening locally and to enforce any observed rule infractions. Further, this example of an excellent "fit" between soft infrastructure (rules) a hard infrastructure (the canals) solves the second order collective action of who is monitoring the monitors. The "goodness of fit" is expressed in the fact that the incentives of the resource users and public infrastructure providers are 
very neatly aligned (attribute of link 2) and eliminate the second order collective action dilemma.

In some systems, such as fisheries, the state of the system (e.g. location and number of fish) is much more costly (perhaps impossible) to measure. This affects the ability of agents in the system to collect information to feed back into the governance system. Not only is the state of the ecology difficult to determine, it might be that the behavior of resource users is difficult to monitor in some systems. If a fisher fishes on the open sea on their own and returns to port with their catch, there is only limited information that can be observed relating to the actual harvesting practices employed by that fisher. An important example is bycatch which is often not reported (Read et al., 2006; Baker et al., 2006). As a consequence of the difficulties with monitoring fishers, some fisheries include an official monitor on each vessel (e.g. Alaska Fisheries Science Center, 2011). Others fisheries have strict gear restrictions that are easy to check in the harbors. This is yet another example of an institutional arrangement that fit the biophysical conditions: it is very easy to assess fishing gear and almost impossible to measure fish stocks. Given these and many other examples of how different types of infrastructure and actors are tightly linked and interact in subtle ways to produce successful governance outcomes, we are tempted to ask if there are general lessons that can be ported from successful SES governance structures to the context of the policy process.

The sheer number of variables, relationships and feedbacks represented in Figures 2, 3, and Table 1, begs the question of how any policy, however narrowly focused could ever work for very long given all that can go wrong. This view presents quite a depressing picture for the policy analyst. On the other hand, policy analysts can take heart in the fact that complex life forms have to address problems of similar levels of complexity, and do so very successfully. Just how complex does the nested, complex system of governance of a living organism, or a SES for that matter, have to be? Ideas from control theory and electrical engineering provide some guidance.

\subsubsection{How do systems cope with disturbances and stress?}

Consider a situation in which there is a clearly defined problem to be solved and in which the linkages between actions and outcomes is perfectly understood. In such a situation, it is posible in theory to generate a control system do achieve any particular policy outcome within the space of possible outcomes conditioned by the biophysical and social constraints. In such "perfect information" cases, policies can be made to literally run like clockwork. Very few real system behave like this - even precisely designed ones. The reason is, we never have perfect information about the state of the system (e.g. we can never know the actual stock level in a fishery), and we never fully understand the causal relationships that generate dynamics in SESs, and there are always exogenous disturbances and stresses impinging upon the system of interest. How can we design policy processes for such situations?

It turns out that all complex biological systems (of which SESs are examples) must cope with uncertainty, stress, and disturbance. As such, complex biological systems with the capacity to adapt to these difficult circumstances have a common feature: they are composed of complex regulatory feedback networks. These distributed, multi-scale networks make the maintenance precise biological processes possible. They also enable the control of uncertain systems, and are used extensively in engineered systems that must function in spite of disturbance and stress (e.g. modern passenger aircraft in the face of air turbulence - see below). A moment's reflection reveals that SESs are feedback systems. Specifically, policies, in the broadest sense are rules (institutions sensu Ostrom $(1990,2005)$ ) that translate information about a system (e.g. state of the environment, demographics, etc.) into action that feeds back into the system. Thus, effecting policies adds feedback loops to (SESs).

Feedback is an extremely powerful tool to create and maintain complexity. Given a particular set of disturbances, SESs can construct policies (feedback controls) to increase performance (output) and robustness (minimize the sensitivity of the system to disturbance and stress). Over time, SESs can become extremely well adapted to a particular biophysical context, including the disturbance and stress associated with it, as 
well as critical policy processes required to implement policies under stress. Consider the case of the tramos in Diaz Ordaz, Mexico studied by Downing (1974) where conflict resolution mechanisms and water rights change from riparian to prior appropriations with the level of environmental stress. More generally, the process through which policy change can occurs should likely be adaptive to exogenous stress and disturbances.

There is one drawback to such fine tuning: feedback systems are known to exhibit inherent robustnessfragility trade-offs (Csete and Doyle, 2002). Irrigation systems provide an important example: human societies can build large-scale physical infrastructure (canals, reservoirs) and social infrastructure (rules for water allocation, canal maintenance) to eliminate sensitivity of food supply to inter-annual variation in local water supplies. However, in so doing, societies become much more vulnerable to low frequency variation in rainfall (the 100 year flood that destroys the irrigation system) and social upheaval. That is, building robustness to certain classes of disturbances and increasing narrowly focused efficiency (e.g. agricultural yield) introduces fragilities in the system. Worse yet, such fragilities typically are hidden from the user by virtue of good design (Csete and Doyle, 2002), and are only exposed through failure. The irrigation systems works extremely well for a century, and no one is thinking about the 100-year flood and subsequent famine until it happens. There is an increasing body of work suggesting that the capacity of systems to cope with stress and disturbance using feedback regulatory networks (policy networks) faces a hard limit (Chandra et al., 2011; Rodriguez et al., 2011). Thus, navigating such performance-robustness, robustness-fragility trade-offs through policy design and policy processes involving learning and exploration are an essential element of public policy.

\subsection{Public Policy Design Principles}

Given the challenges outlined above, what are the practical tools we can use to cope with change and disturbances? Before we address this question from a public policy perspective, we first discuss some practical insights from a comparative analysis of various types of social and biological systems (Janssen and Osnas, 2005). Diversity (a multiplicity of different types of regulatory feedback mechanisms), redundancy (many regulatory mechanisms perform similar functions), and modularity (some regulatory feedback mechanisms are allowed only limited connectivity others) have been shown to be system characteristics that enhance adaptive capacity. Redundancy of components, information, tasks, and connections, enables a system to maintain its function when a component is lost and the redundant component takes over the function.

Redundancy is common in engineered infrastructure systems (both hard and soft) and, and biological systems. The engineered system of a Boeing 777 which has 150,000 different subsystem modules can continue to fly when many modules have been knocked out (Csete and Doyle, 2002). This high level redundancy is necessary to achieve extreme robustness (at great financial expense): ability of the Boeing 777 to continue to function when modules fail is crucial because the cost of overall system failure is so high. This is not the case for, say, a coffee machine whose failure has far less impact on our lives. Coffee machines can be developed at a much lower cost, but with much less robustness. An example of redundancy in institutions is the concurrent use of informal and formal rules for resource management (Low et al., 2003). If informal rules (subsystem modules) fail, progressive layers of formal institutional arrangements (higher-level, more costly subsystem modules that perform a similar function) are activated. Perhaps the most important example of redundancy in biological systems is related to genes. Experiments show that deleting a gene in an organism often has little phenotypic effect due to the existence of duplicate genes (subsystem module) or compensation by alternative metabolic pathways (higher level subsystem module performing a similar function) (Gu et al., 2003).

Modularity provides a system with different functional parts or modules that can evolve somewhat independently. The modules might be loosely linked with each other, but a failure in one module does not severely affect the others, as would happen if they were tightly linked. Sufficient links between modules are required as modules might learn from the activities occurring within other modules. Within the social 
sciences this is referred to as polycentricity. Ostrom et al. (1961) identified a polycentric metropolitan area as having many centers of decision making which were formally independent of each other, but one could learn from experimentation in the other various centers (McGinnis, 1999).

A third general factor is diversity in agents or connections. In organizations a diverse set of connections is important for the creation of a diverse portfolio of knowledge or shared organizational mental models (Staber and Sydow, 2002). In systems with low diversity, there are fewer chances of creating new ideas, components or connections. A population of organisms with the same ability to initiate an immune response will be hit hard when a harmful new disease enters the population. Genetic diversity provides the capacity to create novel antibodies, so at least a few individuals in the population might be able to resist the new disease. Tinkering, mutations, and making errors are essential to generate new components and links in a system (Kirschner and Gerhart, 1998). Importantly, in a modular system, such novelty can be tested without severely disturbing other modules - i.e. experimentation can occur locally without impacting overall system function. If the innovation is beneficial, it might be replicated. In the case of a novel disturbance such as a disease, it is essential that a system is able to generate new responses.

The characteristics of systems that make them robust illustrates the importance of polycentric systems, which enable redundancy, modularity and diversity. Polycentric systems enable institutional arrangements to achieve a better fit with the temporal and ecological dynamics those institutions are intended to govern, as well as with social dynamics and local knowledge. This sounds fine in theory, in practice it is difficult to define boundaries and when multiple ecological services are involved with different spatial and temporal dynamics, decisions have to be made regarding how to juggle the mixed bag of carrots and sticks. Overlapping boundaries and redundancies in responsibilities might be needed to cope with inconsistencies and conflicts of the governance of ecological services.

\section{Conclusions}

In this paper, we have argued that the increasing scale and interconnectedness of human activities have important implications for the policy process. Specifically, we can no longer treat the policy context as fixed on the timescale on which the policy process plays out. Rather, the dynamic feedback between policy and the biophysical context depicted in 1 (B) will become increasingly important as the process of globalization proceeds. This calls for new tools and theories to better understand and inform the public policy process. Here, we have presented two related theoretical frameworks with the potential to contribute to this understanding.

Most of Ostroms work on theoretical frameworks focuses on policies as rules and their functioning in different social and ecological contexts. The policy process of interest to most readers of this journal is not addressed explicitly in either framework discussed here (Figures 2 and 3). However, the policy process is implicit in the institutional rational choice framework in general, and thus in the robustness and SES frameworks in particular: it is an emergent property of a system of actors and rules. Complex notions of advocacy coalitions, learning, beliefs etc. are difficult to address explicitly the SES and robustness frameworks, but they certainly would be observable patterns given a collection of agents, rules, and resources. Thus, the policy process itself is an example of a SES, where the "ecosystem" is mostly human-made as in the welldeveloped concept of "industrial ecosystems". The question is how useful it is to think of the policy process as an SES embedded in broader social, economic, and political settings and related ecosystems as depicted in Figures 2 and 3.

For many policy questions, these frameworks may not add value. However, we suggest there is at least one specific instance where they can: when public policy must cope with deep uncertainty and change in the policy context that occurs on the same time scale as the policy process itself - i.e. sufficiently fast. The main lesson from applying the robustness framework in particular is the notion that one can cope with uncertainty and change, but this will have a price. Developing policies to increase robustness of social- 
ecological systems requires an explicit decision about robustness of what system properties and aspects of performance to what types of exogenous shocks. Once the choice about which vulnerabilities are to be addressed, building robustness requires navigating tradeoffs between short-term efficiency and long-term robustness. Finally, and most importantly, even if these complex trade-offs can be successfully navigated in a policy process there remains a final trade-off about which agents have little choice: Increasing robustness to one type of known disturbance necessarily increases vulnerability to other types of disturbances (Chandra et al., 2011; Csete and Doyle, 2002). Worse yet, these emergent vulnerabilities are largely hidden, revealed only by a system-level failure.

A key message for policy scientists is simply the importance of the acknowledgement that such fundamental robustness-vulnerability tradeoffs exist. The acceptance that policies may, and eventually must, fail immediately follows. Given that fail-free policies cannot be developed, we need to shift thinking away from coalitions advocating for the "right" policy to policy processes that stimulate experimentation, adaptation and learning. In a world of continuous change, policies that are appropriate for some contexts may reveal new vulnerabilities in another context. Policies should therefore be seen as experiments that require systematic, ongoing monitoring and evaluation as elements of regulatory feedback networks. Decentralized experimentation would allow for innovation and increase the probability of achieving a fit between policies and local conditions (modularity and diversity). Governance at higher levels may stimulate a process of information exchange to facilitate learning from local-level experimentation.

A robust SES may exist in the form of a polycentric system where higher levels provide coordination, monitoring and synthesis but hold local level units accountable to reach certain policy outcomes. At the local level there is a certain degree of freedom to craft policies that may lead to desired outcomes, and those policies might be tailored to local conditions. When local governance fails, as it must, higher levels provide support based on knowledge gained from other local conditions (redundancy and diversity). The challenge in terms of policy processes is twofold. First, do local-level governance regimes necessarily exhibit more efficient policy processes? Second, what policy processes are used to determine policy outcomes at the next level? How is it decided what policy outcomes are demanded of the local level? Which actors from across different levels of governance participate in this process? Whether or not such an idealized polycentric system can be implemented, the main lessons from studies of robustness is that successes from the past do not guarantee success in the future. Policy processes must have the capacity to adapt rapidly. Studies of SES, and feedback systems more generally, suggest that multi-level, polycentric governance regimes are essential to match institutions to challenges at the right temporal and organizational scale. What is needed is a "meta" policy process that connects governance regimes across levels to cope with cross-scale interactions that are sure to become more prevalent as the process of globalization plays out over the coming decades.

\section{Acknowledgements}

We acknowledge financial support for this work from the National Science Foundation, grant numbers SES0645789 , SES-0748632 and BCS-1115054.

\section{References}

Adger, W., Eakin, H., and Winkels, A. (2009). Nested and teleconnected vulnerabilities to environmental change. Frontiers in Ecology and the Environment, 7(3):150-157.

Alaska Fisheries Science Center (2011). Fisheries monitoring and analysis, http://www.afsc.noaa.gov/fma/.

Anderies, J., Janssen, M., and Ostrom, E. (2004). A framework to analyze the robustness of social-ecological systems from an institutional perspective. Ecology and Society, 9(1):18. 
Baker, C., Lukoschek, V., Lavery, S., Dalebout, M., Yong-un, M., Endo, T., and Funahashi, N. (2006). Incomplete reporting of whale, dolphin and porpoise bycatchrevealed by molecular monitoring of korean markets. Animal Conservation, 9(4):474-482.

Berkes, F., Colding, J., and Folke, C. (2003). Navigating social-ecological systems: building resilience for complexity and change. Cambridge Univ Pr.

Brock, W., Carpenter, S., Scheffer, M., and of Wisconsin-Madison. Social Systems Research Institute, U. (2005). Regime shifts, environmental signals, uncertainty, and policy choice. Social Systems Research Institute, University of Wisconsin.

Burns, R. (1993). Irrigated rice culture in monsoon asia: The search for an effective water control technology. World Development, 21(5):771-789.

Carpenter, S., Ludwig, D., and Brock, W. (1999). Management of eutrophication for lakes subject to potentially irreversible change. Ecological Applications, 9(3):751-771.

Chandra, F., Buzi, G., and Doyle, J. (2011). Glycolytic oscillations and limits on robust efficiency. Science, 333(6039):187-192.

Clements, F. (1916). Plant succession: an analysis of the development of vegetation. Carnegie Institution of Washington.

Cohen, M., March, J., and Olsen, J. (1972). A garbage can model of organizational choice. Administrative science quarterly, pages 1-25.

Csete, M. E. and Doyle, J. C. (2002). Reverse engineering of biological complexity. Science, 295:16641669.

Downing, T. E. (1974). Irrigation's Impact on Society, chapter Irrigation and Moisture Sensitive Periods: A Zapotec Case., pages 113-122. University of Arizona Press,Tucson, AZ, USA.

Folke, C., Pritchard, L., Berkes, F., Colding, J., and Svedin, U. (2007). The problem of fit between ecosystems and institutions: ten years later. Ecology and society, 12(1):30. [online] URL: http://www.ecologyandsociety.org/vol12/iss1/art30/.

Gu, Z., Steinmetz, L., Gu, X., Scharfe, C., Davis, R., and Li, W. (2003). Role of duplicate genes in genetic robustness against null mutations. Nature, 421(6918):63-66.

Gunderson, L., Peterson, G., and Holling, C. (2008). Practicing adaptive management in complex socialecological systems. Complexity theory for a sustainable future, page 223.

Holling, C. (1973). Resilience and stability of ecological systems. Annual review of ecology and systematics, $4: 1-23$.

Holling, C. (1978). Adaptive environmental assessment and management. Adaptive environmental assessment and management.

Holling, C. (1979). Myths of ecological stability: Resilience and the problem of failure.

Holling, C. and Gunderson, L. (2002). Resilience and adaptive cycles. Panarchy: Understanding transformations in human and natural systems, pages 25-62. 
Holling, C. and Meffe, G. (1996). Command and control and the pathology of natural resource management. Conservation biology, 10(2):328-337.

Kingdon, J. (1984). Agendas, alternatives, and public policies (longman classics edition). Longman Publishing Group.

Kingdon, J. (2002). Agendas, alternatives, and public policies (longman classics edition). Longman Publishing Group.

Kirschner, M. and Gerhart, J. (1998). Evolvability. Proceedings of the National Academy of Sciences, 95(15):8420-8427.

Low, B., Ostrom, E., Simon, C., and Wilson, J. (2003). Redundancy and diversity: do they influence optimal management. Navigating social-ecological systems: building resilience for complexity and change, pages 83-114.

Ludwig, D., Jones, D., and Holling, C. (1978). Qualitative analysis of insect outbreak systems: the spruce budworm and forest. Journal of animal ecology, 47(1):315-332.

Ludwig, D., Walker, B., and Holling, C. (1997). Sustainability, stability, and resilience. Conservation Ecology, 1(1):7.

Maass, A., Anderson, R., et al. (1978). ... and the desert shall rejoice: conflict, growth, and justice in arid environments. MIT Press.

McGinnis, M. (1999). Polycentricity and local public economies. Ann Arbor: University of Michigan Press.

Meinzen-Dick, R. (2007). Beyond panaceas in water institutions. Proceedings of the national Academy of sciences, 104(39):15200-15205.

O'Brien, K. and Leichenko, R. (2000). Double exposure: assessing the impacts of climate change within the context of economic globalization. Global Environmental Change, Part A: Human and Policy Dimensions, 10(3):221-232.

Ostrom, E. (1990). Governing the commons: The evolution of institutions for collective action. Cambridge University Press.

Ostrom, E. (1995). Designing complexity to govern complexity. In Hanna, S. and Munasinghe, M., editors, Property Rights and the Environment: Social and Ecological Issues., pages 33-45. The International Bank for Reconstruction and Development/The World Bank, Washington DC.

Ostrom, E. (1996). Crossing the great divide: coproduction, synergy, and development. World Development, 24(6):1073-1087.

Ostrom, E. (1998). Scales, polycentricity, and incentives: Designing complexity to govern complexity. In Guruswamy, L. D. and McNeely, J., editors, Protection of global biodiversity: Converging strategies, pages 149-67. Duke University Press, Durham, NC.

Ostrom, E. (2005). Understanding institutional diversity. Princeton, NJ: Princeton Univ. Press.

Ostrom, E. (2007). A diagnostic approach for going beyond panaceas. Proceedings of the National Academy of Sciences, 104(39):15181-15187. 
Ostrom, E. (2009). A general framework for analyzing sustainability of social-ecological systems. Science, 325(5939):419-422.

Ostrom, V., Tiebout, C., and Warren, R. (1961). The organization of government in metropolitan areas: a theoretical inquiry. The American Political Science Review, 55(4):831-842.

Parks, R., Baker, P., Kiser, L., Oakerson, R., Ostrom, E., Ostrom, V., Percy, S., Vandivort, M., Whitaker, G., and Wilson, R. (1981). Consumers as coproducers of public services: some economic and institutional considerations. Policy Studies Journal, 9(7):1001-1011.

Read, A., Drinker, P., and Northridge, S. (2006). Bycatch of marine mammals in us and global fisheries. Conservation Biology, 20(1):163-169.

Rodriguez, A., Cifdaloz, O., Anderies, J., Janssen, M., and Dickeson, J. (2011). Confronting management challenges in highly uncertain natural resource systems: a robustness-vulnerability trade-off approach. Environmental Modeling and Assessment, 16(1):15-36.

Sabatier, P. (1988). An advocacy coalition framework of policy change and the role of policy-oriented learning therein. Policy sciences, 21(2):129-168.

Sabatier, P. et al. (1999). Theories of the policy process. Westview Press Boulder, CO, 1 edition.

Sabatier, P. et al. (2007). Theories of the policy process. Westview Press Boulder, CO, 2 edition.

Sabatier, P. and Jenkins-Smith, H. (1993). Policy change and learning: An advocacy coalition framework. Boulder: Westview.

Schlager, E. (1994). Fishers' institutional responses to common-pool resource dilemmas. In Ostrom, E., Gardner, R., and Walker, J., editors, Rules, games, and common-pool resources, pages 247-66. Ann Arbor: University of Michigan Press.

Shivakoti, G., Ostrom, E., et al. (2002). Improving irrigation governance and management in Nepal. ICS Press, Oakland, CA.

Staber, U. and Sydow, J. (2002). Organizational adaptive capacity: A structuration perspective. Journal of Management Inquiry, 11(4):408-424.

Tang, S. (1992). Institutions and collective action: Self-governance in irrigation. ICS press, Oakland, CA.

Vitousek, P., Aber, J., Howarth, R., Likens, G., Matson, P., Schindler, D., Schlesinger, W., and Tilman, D. (1997). Human alteration of the global nitrogen cycle: sources and consequences. Ecological applications, 7(3):737-750.

Weible, C. and Sabatier, P. (2007). A guide to the advocacy coalition framework. In Fischer, F., Miller, G. J., and Sidney, M. S., editors, Handbook of public policy analysis, pages 123-136. Taylor \& Francis.

Wilson, J., Acheson, J., Metcalfe, M., and Kleban, P. (1994). Chaos, complexity and community management of fisheries. Marine Policy, 18(4):291-305.

Young, O. (2002). The institutional dimensions of environmental change: fit, interplay, and scale. MIT Press, Cambridge, MA. 